\title{
Arteries of the head and encephalic base in a case of conjoined twin cattle
}

\author{
Hieronim Frąckowiak, Katarzyna Szczepańska, Maria Nabzdyk, Paweł Pawlak, \\ Maciej Zdun
}

Poznan University of Life Sciences, Department of Anatomy of Animals, Poznań, Poland

\author{
Received January 20, 2015 \\ Accepted November 10, 2015
}

\begin{abstract}
Dicephaly is a peculiar type of conjoined twins, which is observed in cattle and other vertebrates. The analysis demonstrates the course and division of arteries of the cranium of a one-day-old two-headed conjoined calf. In comparison with the normal pattern of the bovine cranial vasculature, the arteries of the head of the conjoined animal were considerably modified. The absence of the arteries found in anatomically normal cattle was compensated by very strong, modified linguofacial trunks located at the place where the animals' heads were conjoined.
\end{abstract}

Brain base arteries, head vascularity, ruminant

Conjoined twins, resulting from a malformation of monozygotic twins, have been known at least since $6500 \mathrm{BC}$ (Mellaart 1962). This condition is caused by an incomplete division of the embryo during the embryogenesis (Wagner et al. 2013).

Dicephaly (dicephalus; two-headed monster) is a peculiar type of conjoined twins observed in cattle (Cornillie et al. 2006; Ćítek et al. 2009). The case of a two-headed bull shark described by Wagner et al. (2013) proves that this malformation has a universal character in vertebrates.

In spite of the description of conjoined twins in various species of animals including the dog (Nottidge et al. 2007), sheep (Spiers et al. 2010; Omobowale et al. 2014), goat (Shojaei et al. 2012), pigeon (Corbera et al. 2012) and shark (Wagner et al. 2013), there is a lack of analyses of the arterial architecture of the areas of abnormalities.

The aim of this study was to describe the arterial vascularisation in a case of conjoined twin cattle, including the arteries of the encephalic base, and to compare this pattern with the anatomically normal head vascularisation in the same species.

\section{Materials and Methods}

The research was conducted on a one-day-old, two-headed conjoined still-born bull calf with five limbs, born from a Polish Red-and-White cow of the Bos taurus species. A Caesarean section was carried out during calving. The investigation was conducted on a corrosion preparation of the vessels on a bone scaffold. For this purpose the arteries of the animal under investigation were filled with acetone-dissolved stained vinyl superchloride. The injection mass was infused through the heart into the brachiocephalic trunk by means of an air-cushioned syringe at a pressure of 60-80 kPa. After about 40 days the mass had hardened and the heads were enzymatically macerated (Persil ${ }^{\circledR}$ - Henkel, Düsseldorf, Germany) at a temperature of $38^{\circ} \mathrm{C}$. The resulting corrosion preparations were used to analyse the course, division and connections of arteries in relation to the bone scaffold of the cranium (skeletotopia).

The anatomical nomenclature used conformed to an illustrated elaboration on the anatomical nomenclature (Simoens 1978-1979).

\section{Results}

The heads were conjoined in the atlanto-occipital region. The vertebrae of the cervical, thoracic, lumbar, sacral and caudal spine were present as a single set. The investigation

Address for correspondence:

Hieronim Frąckowiak

Department of Anatomy of Animals

Poznan University of Life Sciences

Wojska Polskiego 71c, 60-625, Poznań, Poland

Phone: +48 618487631

E-mail: hierofro@au.poznan.pl

http://actavet.vfu.cz/ 
revealed that there was a left common carotid artery and a right common carotid artery located on both sides of the single neck. Both the left and right common carotid arteries diverged from the brachiocephalic trunk, conforming to a normal ramification pattern of these arteries in cattle.

There were typical branches diverging from either common carotid artery, i.e. the cranial thyroid artery, which, apart from the branch leading to the thyroid gland, also split into the ascending pharyngeal artery and the cranial laryngeal artery.

The terminal division of the bilateral common carotid arteries resulted in the formation of an internal carotid artery and an external carotid artery.

The internal carotid artery was thin and was linked to the rostral epidural rete mirabile located in the cranial cavity.

The right and left external carotid arteries were direct extensions of the common carotid arteries and either of them coursed rostrolaterally to the external aspect of the corresponding conjoined head and continued to the medial surface of the right mandible of the right head and the left mandible of the left head, respectively.

There were no external carotid arteries situated medially in between the conjoined heads, i.e., next to the contralateral mandibles. The left external carotid artery of the right head and the right external carotid artery of the left head were absent and their functions were taken over by modified linguofacial trunks.

The left and right external carotid arteries branched successively into the ipsilateral linguofacial trunk, caudal auricular artery and superficial temporal artery, and continued each in a maxillary artery. All those arteries divided secondarily into the branches which were typical of the bovine species. The condylar artery, which was a branch of the occipital artery located on the squama of the occipital bone, was linked to the caudal epidural rete mirabile. The occipital artery arose from the internal carotid artery.

The left and right maxillary arteries were direct extensions of the corresponding external carotid arteries and divided into numerous branches gathered in three clusters.

The first cluster of branches was composed of the inferior alveolar artery entering the mandibular canal, the caudal branch entering the rostral epidural rete mirabile, the temporomandibular articular branch, and pterygoid branches.

The second cluster of branches of the maxillary artery was composed of the buccal artery, the external ophthalmic artery and a number of rostral arteries leading to the rostral epidural rete mirabile.

The external ophthalmic artery entered the orbit and formed the ophthalmic rete mirabile in its course. It branched into the external ethmoidal artery, the lacrimal artery and the supraorbital artery which passed through the supraorbital foramen to the external surface of the frontal bone.

The presence of a rostral epidural rete mirabile, which surrounded the bottom of the pituitary gland, was observed in each cranial cavity. Each of these retia mirabilia was paired (Plate I, Fig. 1). One part of each of both retia was connected with the rostral branches and the caudal branch to the rostral epidural rete mirabile, whereas the contralateral part received the branches of the modified linguofacial trunk. The intracranial supraretial segment of the internal carotid artery emerged from the rostral epidural rete mirabile. The division of this segment contributed to the development of a cerebral arterial circle. In either of the two cranial cavities the cerebral arterial circle was asymmetrical because the lateral rostral cerebral artery and the lateral caudal communicating artery were larger in diameter than the corresponding contralateral arteries, which were located medially in the region where the heads were conjoined. Both cerebral arterial circles gave rise to the typical branches, i.e. the middle cerebral artery, rostral choroidal artery, caudal cerebral artery and rostral cerebellar arteries, while the caudal cerebellar arteries arose from either basilar artery. 
The rostral epidural retia mirabilia located in both cranial cavities merged caudally with the caudal epidural rete mirabile, which was a single network as the result of the fusion of the bilateral retia. This caudal rete mirabile was characteristically V-shaped and its single main part was located on the basilar part of the occipital bone. It bifurcated into two branches and either branch merged with the rostral epidural rete mirabile located in either of the two cranial cavities. The caudal epidural rete mirabile was linked to the condylar artery.

The last cluster of branches of the right-side maxillary artery of the right head (located at the rostral edge of the mandibular branch) was composed of a descending palatine artery, a malar artery, an infraorbital artery and a sphenopalatine artery. On the left side of left head the sphenopalatine artery arose from the descending palatine artery. The branches diverging from those arteries were located on the bone scaffold of the hard palate, supplied blood to the infraorbital region and entered the nasal cavity, respectively.

The modified linguofacial trunks were considerably elongated and large in diameter. They compensated for the absence of the external carotid and maxillary arteries on the medial sides of both conjoined heads which were adjacent to each other.

The modified left linguofacial trunk of the right head was much longer than the modified right linguofacial trunk of the left head.

The modified right linguofacial trunk, which was formed from the extension of the linguofacial trunk of the right head, ran diagonally to the left side and came out on the facial surface, in the midline at the place where both branches of the mandibles of the conjoined heads contacted each other (Plate I, Fig. 2). It was a large vessel, with a similar diameter as that of the arterial stem from which extended. The artery ran arched upwards, bent and split into numerous vessels at the place of the angle formed by the two conjoined frontal bones. It branched into three clusters, each cluster into two vessels - one vessel for either head (Plate II, Figs 3 and 4).

The first cluster bifurcated sideways and upwards, ran towards the frontal region.

The second cluster ran almost horizontally and entered the cranial cavity through the foramen formed at the angle of the conjoined heads of the two specimens. The diameter of the vessel on the right was a few times larger than the one on the left.

The third cluster ran caudally towards the cranial cavity, using the space in the mandibular notch to form the final fragment of modified maxillary arteries, which were absent from those surfaces as extended vessels of the external carotid artery. The final fragment of modified maxillary arteries correspond to areas of supply by maxillary arteries. In this case the vessel on the left side was expressed much more strongly.

The modified left linguofacial trunk (Plate II, Fig. 4) was much shorter than the right one. It was an extension of the left linguofacial trunk and was noticeably weaker than the parent stem from which it arose.

The modified left linguofacial trunk gave rise to the arteries to the tongue of the left head and the inferior labial artery of the right head and then it split into two facial arteries (one vessel for either head) and into superior and inferior labial arteries.

\section{Discussion}

In accordance with the study by Cornillie et al. (2006), the congenital malformation described here was qualified as a case of specimens conjoined in the atlanto-occipital region, with simultaneous connection of the vertebrae in the thoracic and lumbar spine.

The arteries of the head and encephalic base of the conjoined animal were compared with the cranial vascular patterns in anatomically normal cattle (König 1979; Nickel et al. 1996; Frąckowiak 2003; Zdun et al. 2013, 2014).

Our investigations proved that the left and right common carotid arteries were located in the single neck and diverged from the brachiocephalic trunk, supplying blood to both 
heads of the conjoined animal. The common carotid arteries ramified into typical branches of the species and finally split into the external carotid artery and the internal carotid artery. During ontogenesis in cattle the extracranial part of the internal carotid artery is completely obliterated (König 1979; Nickel et al. 1996; Frąckowiak 2003; Zdun et al. 2013). In new-born and young cattle the internal carotid artery is still fully retained, as was observed in research on the conjoined animal. The intracranial segment of the internal carotid artery, however, is still fully retained in cattle at all ontogenetic periods. This segment of the internal carotid artery emerges from the rostral epidural rete mirabile and finally splits into the rostral cerebral artery and the caudal communicating artery, which are segments of the cerebral arterial circle (König 1979; Nickel et al. 1996; Frąckowiak 2003; Zdun et al. 2013).

In the present case, the external carotid arteries, which extended from the common carotid arteries, started as bilateral arterial trunks located on the external sides of the heads of the conjoined animal. The right external carotid artery was located at the right mandible of the right head, whereas the left external carotid artery was located at the left mandible of the left head. The bilateral external carotid arteries continued into maxillary arteries. Both of the abovementioned main arteries of the head split into the branches which were typical of cattle (Frąckowiak 2003).

The left external carotid artery of the right head and the right external carotid artery of the left head were absent and their functions were taken over by modified linguofacial trunks. Those arteries were very strong and they formed numerous branches compensating for the absence of the arteries which are observed in anatomically normal cattle.

The last bilateral cluster of branches arising from the maxillary artery consisted of the descending palatine artery, the infraorbital artery, and the sphenopalatine artery (the right side). This pattern of the final division of the maxillary artery, which was observed in the conjoined animal, was different from the described cattle model and was similar to the vascular pattern described in a banteng (Frąckowiak 1987).

In comparison with anatomically normal cattle the arteries of the head of the conjoined animal were considerably modified. The presentation and description of this case may provide insight for future vascular investigations, particularly in pathologically changed areas of the body. There are no previous studies available describing such an unusual and unique case as this.

\section{References}

Čítek J, Řehout V, Hájková J 2009: Congenital disorders in the cattle population of the Czech Republic. Czech J Anim Sci 54: 55-64

Corbera JA, Morales I, Arencibia A, Morales M, Gutiérrez C 2012: Caudal duplication (dipygus) in a Rock Pigeon (Columbia livia). Eur J Anat 16: 221-223

Cornillie P, Jacobs C, Breugelmans S, Simoens P 2006: Abnormal connections between the digestive tract and respiratory system is a frequent finding in decephalic calves. Ital J Anat Embryol suppl 1: 99-99

Frąckowiak H 1987: Arteries of the head of banteng (Bos javanicus D Alton, 1823) (in Polish). Roczniki AR Poznań 35: 33-40

Frackowiak H 2003: Arterial roads of the head in selected mammalian orders (in Polish). Roczniki AR Poznań 336: $5-80$

Mellaart J 1962: Excavations at Çatal Hüyük, 1961, First Preliminary Report. Anatolian Studies 12: 41-65

König HE 1979: Anatomy and the development of blood vessels in the cranial cavity of domestic ruminants (cattle, sheep and goat) (in German). Enke Verl, Stuttgart, 215 p.

Nickel R, Schummer A, Seiferle E 1996: Textbook of the domestic animals anatomy. Volume 3 angiology, skin, skin structure (in German). Parey Buchverlag, Berlin, pp 105-121

Nottidge HO, Omobowale TO, Olopade JO, Oladiran OO, Ajala OO 2007: A case of craniothoracopagus (monocephalus thoracopagus tetrabrachius) in a dog. Anat Histol Embryol 36: 179-181

Omobowale TO, Igado OO, Abiola JO, Adeniji SA, Omirinde JO 2014: Craniofacial duplication (diprosopus) in a domestic lamb (Ovis aries). J Vet Anat 7: 57-61

Shojaei B, Mohebbi E, Hashemnia S 2012: Caudal duplication (monocephalus tripus dibrachius) in a kid goat. Eur J Anat 16: 206-211 
Simoens P 1978-1979: Illustrated anatomical nomenclature of the heart and the arteries of head and neck in the domestic mammals. Mededelingen van de Faculteit Diegeneeskunde Rijksuniv, Gent, pp 1-100

Spiers ZB, Biddle AJ, Gabor MJ, Lee E, Gabor LJ 2010: Monocephalic thoracopagus tetrabrachius in twin lambs. Can Vet J 51: 1037-1039

Wagner CM, Rice PH, Pease AP 2013: First record of dicephalia in a bull shark Carcharhinus leucas (Chondrichthyes: Carcharhinidae) foetus from the Gulf of Mexico, U.S.A. J Fish Biol 82: 1419-1422

Zdun M, Frąckowiak H, Kiełtyka-Kurc A, Kowalczyk K, Nabzdyk M, Timm A 2013: The arteries of brain base in species of bovini tribe. Anat Rec (Hoboken) 11: 1677-1682

Zdun M, Frąckowiak H, Kowalczyk K, Maryniak H, Kiełtyka-Kurc A 2014: Comparative analysis of the course of the facial and transverse facial arteries in selected ruminant species. Ann Anat 196: 129-134 
Plate I

Frąckowiak H. et al.: Arteries of the head ... pp. 3-7

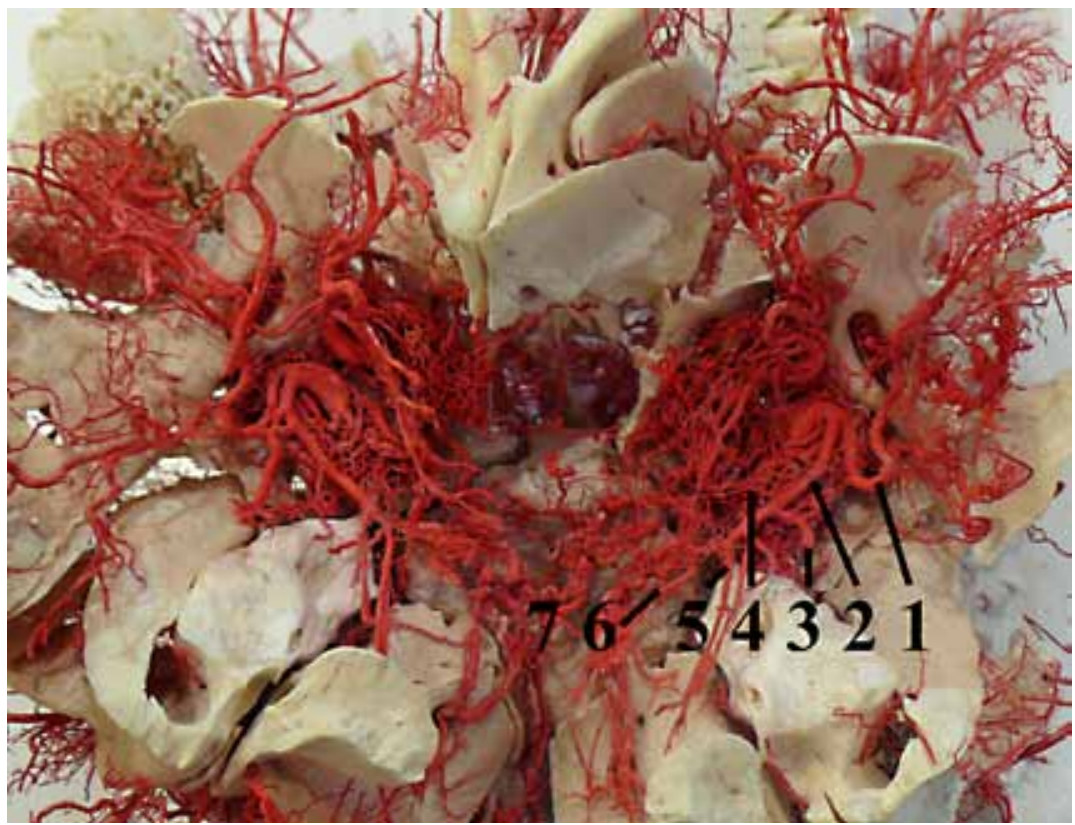

Fig. 1. Dorsal view of the arterial circles of the brain of the conjoined twin cattle:

1 - rostral cerebral artery; 2 - caudal communicating artery; 3 - caudal cerebral artery; 4 - rostral epidural rete mirabile; 5 - rostral cerebellar artery; 6 - basilar artery; 7 - caudal epidural rete mirabile

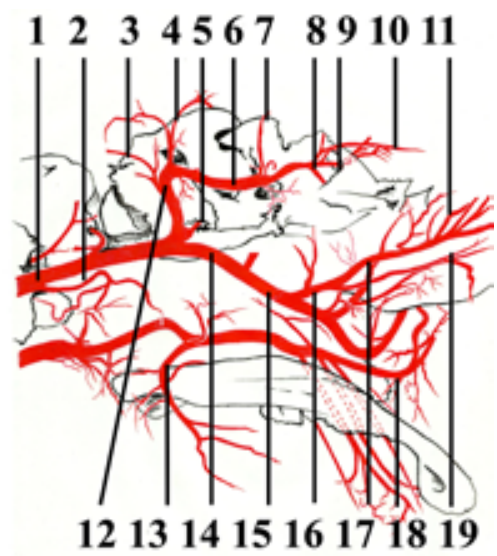

Fig. 2. Oblique ventral view of the carotid arteries and their branches:

1 - right common carotid artery; 2 - right cranial thyroid artery; 3 - right caudal auricular artery; 4 - right superficial temporal artery; 5 - right internal carotid artery; 6 - right maxillary artery, 7 - right external ophthalmic artery; 8 - right greater palatine artery; 9 - right sphenopalatine artery; 10 - right infraorbital artery; 11 - right dorsal lingual branches; 12 - right external carotid artery; 13 - left facial artery; 14 - right linguofacial trunk; 15 - modified right linguofacial trunk; 16 - right lingual artery; 17 - right deep lingual artery; 18 - modified left linguofacial trunk; 19 - right sublingual artery 


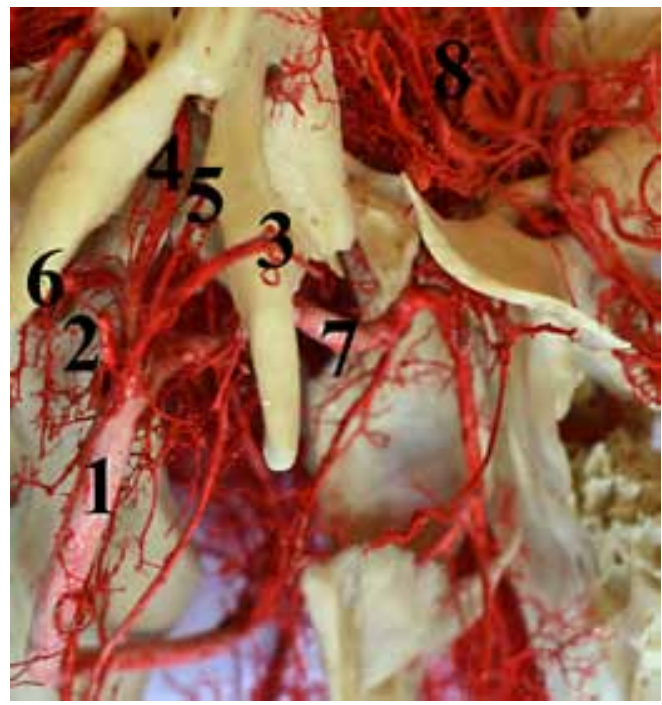

Fig. 3. The final fragment of the modified right linguofacial trunk and it branches:

1 - modified linguofacial trunk; 2 and 3 - the first cluster of modified linguofacial trunk - vessels for the frontal region: 2 - for right head, 3 - for left head; 4 and 5 - second cluster of modified linguofacial trunk - vessels entered the cranial cavity: 4 - for right head, 5 - for left head; 6 and 7 - last cluster of modified linguofacial trunk: 6 - modified right maxillary artery, 7 - modified left maxillary artery; 8 - left arterial circle of the brain

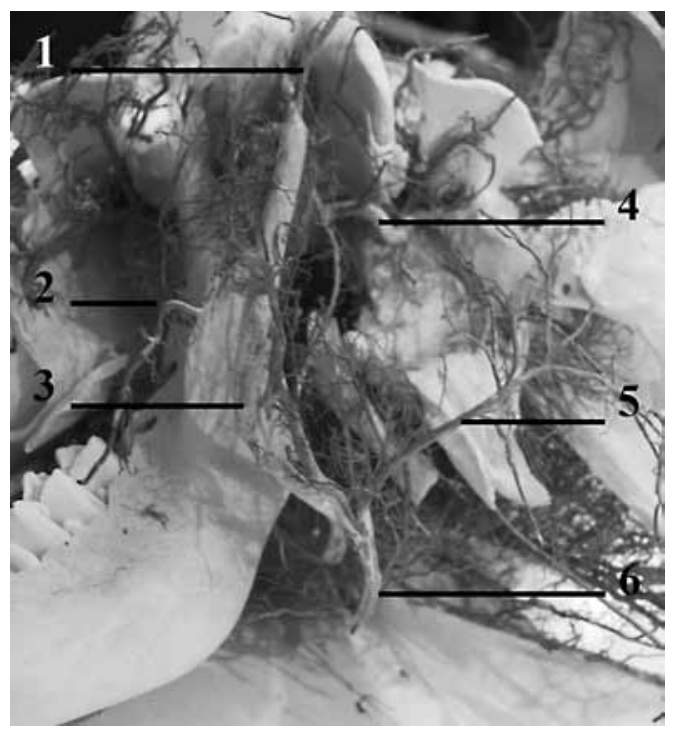

Fig. 4. The modified right and left linguofacial trunks and their branches (front view of conjoined heads):

1 - artery running towards the frontal region from modified right linguofacial trunk (left head); 2 - facial artery from modified left linguofacial trunk (right head); 3 - modified right linguofacial trunk; 4 - modified maxillary artery from modified right linguofacial trunk (left head); 5 -facial artery from modified left linguofacial trunk (left head); 6 - modified left linguofacial trunk 